\title{
Sociodemographic Predictors of Health-Related Quality of Life and Healthcare Service Utilisation among Young Refugees in South Australia
}

\author{
Tahereh Ziaian1*, Helena de Anstiss², Georgia Antoniou ${ }^{3}$, Teresa Puvimanasinghe1, \\ Peter Baghurst ${ }^{4}$ \\ ${ }^{1}$ University of South Australia-City East Campus North Terrace, Adelaide, Australia \\ ${ }^{2}$ University of South Australia-Magill Campus North Terrace, Adelaide, Australia \\ ${ }^{3}$ Women's and Children's Hospital Children, Youth and Women's Health Service, Adelaide, Australia \\ ${ }^{4}$ School of Public Health, University of Adelaide, Adelaide, Australia \\ Email: tahereh.ziaian@unisa.edu.au,helena.deanstiss@unisa.edu.au, \\ georgia.antoniou@health.sa.gov.au, teresa.puvimanasinghe@adelaide.edu.au, \\ peter.baghurst@cywhs.sa.gov.au
}

Received 18 October 2015; accepted 22 December 2015; published 25 December 2015

Copyright (C) 2016 by authors and Scientific Research Publishing Inc.

This work is licensed under the Creative Commons Attribution International License (CC BY).

http://creativecommons.org/licenses/by/4.0/

(c) (i)

Open Access

\begin{abstract}
Although refugee adolescents and children are recognised as a health risk population, few studies have explored their Health-related Quality of Life (HRQOL). The present study investigated 1) the sociodemographic predictors of HRQOL such as ethnicity, trauma exposure, and length of residency in Australia in a multiethnic paediatric population with refugee experiences and 2) the relationship between mental healthcare utilisation and HRQOL. Method: Participants were 458 adolescents and children, aged 4 - 17 years, living in South Australia. Parents provided data across the sample and adolescents also completed questionnaires. Overall HRQOL and its composite functional dimensions were assessed using the Paediatric Quality of Life (PedsQL) instrument. Questions from the Child and Adolescent Component of the Australian National Survey of Mental Health and Wellbeing were used to assess service utilisation. Results: Migration region/ethnicity predicted better HRQOL as well as physical, emotional and psychosocial functioning for both children and adolescents. African youths indicated higher HRQOL than those from the former Yugoslavia and the Middle East/South Asia respectively. Pre-migration trauma exposure was associated with lower HRQOL; and longer stay in Australia was related to lower emotional functioning in children. There was a negative association between healthcare service utilisation and PedsQL scores, with participants accessing services demonstrating lower HRQOL. Conclusion: Using more rigorous
\end{abstract}

\footnotetext{
${ }^{*}$ Corresponding author.
} 
methods, future research is needed to investigate additional sociodemographic predictors of HRQOL, and protective/risk factors that impact on HRQOL of young refugees.

\author{
Keywords
}

Refugees, Adolescents, Children, Quality of Life, PedsQL, Healthcare Service Utilisation, Australia

\title{
1. Introduction
}

By mid-2014, war and political violence had resulted in 16.7 million people seeking refuge across international borders [1]. Of the humanitarian entrants arriving in Australia, approximately $40 \%-45 \%$ of them were children and adolescents [2].

Notwithstanding a growing literature on the mental health of refugee children and youth, there has been a focus on a few extreme responses to war-related trauma such as posttraumatic stress disorder (PTSD) and major depression [3] [4]. However the consequences of the refugee experience are far more complex than PTSD and depression. Besides, the majority of refugee youths do not develop psychiatric problems despite their traumatic experiences [5] and those who received such diagnoses tend to indicate improvement over time [6].

Health-related Quality of Life (HRQOL), including the physical, psychological, and social dimensions of health and wellbeing as well as school functioning, is an important measure of the health impacts of the refugee experience. Data on HRQOL can serve a range of purposes including identifying individuals and groups at high risk of health problems, determining the allocation of healthcare resources, evaluating the healthcare needs of communities, and assessing the effectiveness of prevention and intervention programs [7]. HRQOL also allows for a more holistic approach to wellbeing and thus is more acceptable and meaningful to culturally and ethnically diverse populations, including refugees. Although refugee children and adolescents could be a population with elevated risk for health problems due to adverse pre-migratory and post-migratory experiences, few studies have explored their HRQOL including risk and protective factors of HRQOL.

A systematic review of the literature with a sample of 44 studies and more than 5000 children/youth identified resilience and protective factors of mental health including young age at the time of trauma, positive psychological wellbeing of parents/caregivers, family, peer and social support, religious beliefs, and integration into the host community [8]. The same review reported factors such as traumatic experiences, parental exposure to violence, loss of a parent, limited family support, violence and discrimination in the host country, and feeling disconnected to school and neighbourhood increased the risk for adverse mental health in refugee children and youth [8].

Mental health services are often underutilised by refugee children and adolescents owing to a range of cultural, linguistic and service related barriers [9]. For example, a recent Australian study found that only $21.5 \%$ of refugee children and adolescents with depressive symptomatology and only $13 \%$ with emotional and behavioural problems accessed professional help for their problems [10] [11]. Earlier a survey with 4 - 17 years old Australians found that only $25 \%$ of those with mental health concerns had attended a professional service during the six months prior to the study [12].

The present study assessed HRQOL in a multiethnic paediatric population with refugee experiences. Study aims were to: 1) determine the sociodemographic predictors of HRQOL including ethnicity, and length of stay in Australia; and 2) assess the relationship between access to mental healthcare services and HRQOL. Practice and policy implications of the study findings are also discussed.

\section{Method}

\subsection{Participants}

Information was obtained from parents and primary caregivers of children and adolescents aged 4 - 17 years $(\mathrm{n}=$ 510) and from adolescents in the sample aged 13 - 17 years $(n=208)$. In most cases, the person completing the parent questionnaire was the child's biological mother. Participation was limited to those who arrived or whose parents had entered Australia under Australia's Refugee Program between June 1996 and June 2007. The com- 
munities participants belonged to were among the leading refugee source countries (i.e. countries producing the highest number of refugees) during this time period, in Australia (see results for participants' communities). The lack of availability of a complete sampling frame necessitated the use of convenience and snowball sampling. Participants were recruited through refugee settlement agencies, community groups, schools, and ethnic media.

\subsection{Measures}

HRQOL was measured using the 23-item Paediatric Quality of Life Inventory (PedsQL) [7] [13] [14]. The PedsQL assesses physical functioning (8 items) (e.g. hard to do chores around house), emotional functioning (5 items) (e.g. feel afraid or scared), social functioning (5 items) (e.g. trouble getting along with peers), and school functioning (5 items) (e.g. trouble keeping up with school work). The PedsQL comprises a child self-report and a parent-report which assesses the parent's perceptions of the child's HRQOL. In the present study, only the adolescent group (individuals 13 - 17 years old) completed the child self-report while a parent/caregiver report was completed for participates of all ages.

Items on the parent and adolescent form call for one of five possible responses: $0=$ never a problem; $1=\mathrm{al}-$ most never a problem; $2=$ sometimes a problem; $3=$ often a problem; $4=$ almost always a problem. Items were reverse-scored and linearly transformed to a 0 - 100 scale $(0=100,1=75,2=50,3=25,4=0)$, with higher scores indicating better HRQOL. If more than $50 \%$ of the items in the scale were missing, the score was not calculated. Summary scores were calculated for physical health and psychosocial health. The physical health summary score (8 items) is also the physical functioning scale. The psychosocial health summary score (15 items) is the mean calculated by summing the items completed in the emotional, social, and school functioning scales and dividing that sum by the number of items completed [7]. Cut-off point scores for total scale scores has also been calculated for child/adolescent self-reports (69.7) and parent proxy-reports (65.4); indicating that participants obtaining a score below the cut-off point could be especially at risk for poor health outcomes.

Internal consistency for the PedsQL total scale score was $\alpha=0.88$ for child and $\alpha=0.90$ for parent-report; and together with the physical health summary score ( $\alpha=0.80$, child; $\alpha=0.88$, parent), and psychosocial health summary score ( $\alpha=0.83$, child; $\alpha=0.86$, parent), were deemed suitable for group comparisons [7] [13] [14].

Validity of the PedsQL instrument has been demonstrated by: distinguishing between groups that are healthy versus groups with chronic health conditions (i.e. known-groups method); correlations with indicators of morbidity and illness burden; and factor analysis [14]. Though, cross-cultural validity of the PedsQL has not been established for the participant groups in the present study, the scale and/or adaptations of the scale have been validated with other culturally and linguistically diverse (CaLD) paediatric populations. For example, when Gkoltsiou, Dimitrakaki [15] measured the HRQOL of Greek children, they found that the Greek version of the PedsQL had a satisfactory reliability with Cronbach's $\alpha$ exceeding 0.70 (except in self-reported Physical Functioning; $\alpha=0.65$ ). Test-retest stability intraclass correlation coefficients (ICCs) were above 0.60 in all subscales. Additionally, healthy children scored significantly higher on all scales than those with chronic illnesses, and lower socioeconomic groups scoring significantly lower than higher socioeconomic groups. Similarly, Roizen [16] found that the internal consistency for the Argentinian Spanish version of the PedsQL's total and subscale scores exceeded Cronbach's $\alpha$ of 0.70 for self-reports of children over age 8 and parent-reports of children over 5 years. The PedsQL also discriminated between healthy and chronically ill children (72.72 and 66.87, for healthy and ill children, respectively, $p=0.01$ ), between different chronic health conditions, and children from lower socioeconomic status. Furthermore, Roizen [16] found that the PedsQL scale was easy to administer, could be completed without, or with minimal, help by most children and parents, and required only a brief administration time (average 5 - 6 minutes).

Participants' sociodemographic information was also collected including age, gender, language, region/ethnicity, religion, employment status, household income, family composition, and date of arrival in Australia. For purposes of analyses, length of stay was categorised based on the number of years spent in Australia (i.e. more than 5 years; 2 - 5 years; less than 2 years). Participants acknowledging pre-migration trauma were asked to select one or more items from a list of 24 potentially traumatising events adapted from the Migration and Settlement Questionnaire (MASQ; Minas \& Klimidis, unpublished) (e.g. witnessing someone being badly injured or killed). Service utilisation was assessed using questions developed for the Child and Adolescent Component of the Australian National Survey of Mental Health and Wellbeing [12]. These questions assess participants' use of mental health services during the previous six months including school-based services, health and community services, outpatient hospital-based services, and other formal service settings. 


\subsection{Procedure}

The instruments were translated into the target languages (Arabic, Bosnian, Serbian, Dinka, and Persian) by an accredited translator and back-translated by an independent bilingual professional from the corresponding communities. The data were collected by 20 trained bilingual lay interviewers from ethnic backgrounds similar to the participants. This study was approved by the ethics committees of the University of South Australia, the Women's and Children’s Hospital, and the South Australian Department of Education and Children’s Services.

\subsection{Statistical Analysis}

Intercooled Stata 10.1 for Windows was used to perform data analysis. Descriptive statistics were used to describe the demographic features of the study populations and their PedsQL scores. Regression modelling carried out to examine the relationships between the key variables. An initial comparison was made comparing the distributions of Achenbach scores for all groups using both graphical techniques (e.g., cumulative distribution plots) and statistical tests of significance on transformed scores. The association between region/ethnicity and PedsQL total score for adolescent self-reports were also examined. As the total scores and factor scores were significantly skewed, nonparametric tests including Spearman's rho and the Kruskal-Wallis Rank Test were used to test relationships between sociodemographic variables, service utilisation, and PedsQL.

\section{Results}

Of the total participants recruited, 46 (2 adolescents, 5 adolescent's parents and 39 children's parents) failed to answer at least $50 \%$ of the total and/or factor scale items and were excluded from the study. To enhance the clarity of analyses, only adolescents who had fully completed corresponding parent-reports (and vice versa) were included in the study.

\subsection{Descriptive Statistics}

In total, 277 children aged 4 - 12 and 181 adolescents aged 13 - 17 were assessed by their parents, resulting in a total of 458 participants. Of the children and adolescents assessed, 205 (44.8\%) were from the Middle East and South Asia (Iran, Iraq and Afghanistan), 91 (19.9\%) from the former Republic of Yugoslavia (Bosnia and Serbia), and 162 (35.4\%) from Northern and Western Africa (Sudan and Liberia). Languages spoken included Bosnian, Serbian (former Yugoslavia), Arabic, Dari, Persian (Middle East/South Asia), Dinka (Sudan), and English (Liberia). Most participants identified their religion as either Christian (50.0\%) or Muslim (37.61\%). Females comprised $53.3 \%$ of the sample whereas $46.7 \%$ were male. The median (interquartile range) age for the $4-12$ age group was 9.2 years (3.68); and 15.6 years (2.47) for the 13 - 17 age group. Approximately 90.2\% of adolescents and children lived with parents who were either unemployed or relied on government payments as their main source of income, 25.2\% lived in households headed by a single parent/caregiver, and 59.8\% had lived in Australia for less than five years prior to the survey. Sociodemographic details of adolescent and child participants are shown in Table 1.

\subsection{Paediatric Quality of Life}

Table 2 depicts the median (interquartile range) for PedsQL total, factor, and summary scores for adolescents (parent- and self-reports) and children (parent-reports only). It is noteworthy that only 28 (15.5\%) adolescents and $36(13 \%)$ children according to parent-reports, and $21(11.6 \%)$ adolescents according to self-report were below the cut-off point scores of 69.7 (for child/adolescent self-reports) and 65.4 (for parent-reports) calculated for the general population of young people [7]. In the adolescent group, there was good concordance between parent-reports, and adolescent self-reports on total scores $\left(r_{s}=0.65, p=0.0000\right)$, all factor scores and summary scores: in the physical $\left(r_{s}=0.60, p=0.0000\right)$, emotional $\left(r_{s}=0.61, p=0.0000\right)$, social $\left(r_{s}=0.42, p=0.0000\right)$, $\operatorname{school}\left(r_{s}=0.53, p=0.0000\right)$, and psychosocial $\left(r_{s}=0.62, p=0.0000\right)$ dimensions.

\subsection{Sociodemographic Correlates}

Table 3 demonstrates a similar pattern in the relationship between PedsQL total scores and migration region/ethnicity across the parent-reports for adolescents and children with significant regional differences in 
Table 1. Sociodemographic characteristics of adolescents (13 - 17 years) and children (4 - 12 years).

\begin{tabular}{|c|c|c|}
\hline Children $(\mathrm{N}=277)$ & & Adolescents $(\mathrm{N}=181)$ \\
\hline \multirow[t]{2}{*}{$9.2(3.68)$} & Age (median) & $15.6(2.47)$ \\
\hline & Gender (\%) & \\
\hline 55.23 & Female & 50.02 \\
\hline \multirow[t]{2}{*}{44.77} & Male & 49.72 \\
\hline & Migration Region (\%) & \\
\hline 42.24 & Middle East (Iran/Iraq/Afghanistan) & 48.62 \\
\hline 19.86 & Former Yugoslavia & 19.89 \\
\hline \multirow[t]{2}{*}{37.90} & Africa (Sudan/Liberia) & 31.49 \\
\hline & Religion (\%) & \\
\hline 36.86 & Muslim & 35.03 \\
\hline 48.18 & Christian & 43.50 \\
\hline 10.21 & Other religion & 11.86 \\
\hline 1.46 & No religion & 1.69 \\
\hline \multirow[t]{2}{*}{3.29} & missing & 7.92 \\
\hline & Years Living in Australia (\%) & \\
\hline 9.17 & Less than 2 years & 50.28 \\
\hline 62.09 & 2 to 5 years & 32.60 \\
\hline 21.24 & More than 5 years & 12.70 \\
\hline 7.50 & Not disclosed & 4.42 \\
\hline
\end{tabular}

Table 2. Summary statistics for total, subscale and summary scores obtained by adolescents (13 - 17 years) and children (4 12 years) on the Paediatric Quality of Life (PedsQL) instrument.

\begin{tabular}{|c|c|c|c|}
\hline & \multicolumn{2}{|c|}{ Adolescents } & \multirow{2}{*}{$\begin{array}{c}\text { Children } \\
\text { Parent-reports } \\
\text { Max N = 277 }\end{array}$} \\
\hline & $\begin{array}{l}\text { Parent-reports } \\
\text { Max N = } 181\end{array}$ & $\begin{array}{l}\text { Self-reports } \\
\text { Max N = } 181\end{array}$ & \\
\hline \multicolumn{4}{|c|}{ PedsQL total } \\
\hline Median (iqr) & $86.96(23.91)$ & 89.77 (17.39) & 88.04 (18.48) \\
\hline \multicolumn{4}{|c|}{ Physical functioning } \\
\hline Median (iqr) & $96.88(21.88)$ & $96.88(12.50)$ & 93.75 (18.75) \\
\hline \multicolumn{4}{|c|}{ Emotional functioning } \\
\hline Median (iqr) & $90(35)$ & $90(30)$ & $90(25)$ \\
\hline \multicolumn{4}{|c|}{ Social functioning } \\
\hline Median (iqr) & $90(30)$ & $95(20)$ & $90(25)$ \\
\hline \multicolumn{4}{|c|}{ School functioning } \\
\hline Median (iqr) & 79.17 (37.5) & $85(30)$ & $85(30)$ \\
\hline \multicolumn{4}{|c|}{ Psychosocial functioning } \\
\hline Median (iqr) & 85 (28.33) & 87.08 (21.67) & 86.67 (23.33) \\
\hline
\end{tabular}

Note: iqr = interquartile range.

parent total scores for adolescents $\left(\chi^{2}=9.38 ; p=0.009\right)$ and children $\left(\chi^{2}=13.97 ; p=0.001\right)$. The association between region/ethnicity and PedsQL total score for adolescent self-reports approached significance $\chi^{2}=5.88$; $p=0.053$ ). Participants from Africa indicated the greatest HRQOL; followed by youth from former Yugoslavia and the Middle East respectively (see Table 3).

In both age groups significant regional/ethnic differences were also found in parent-reports for physical 
Table 3. Median paediatric quality of life (PedsQL) scores for adolescents (13 - 17 years) and children (4 - 12 years) across migration region, pre-migration trauma and length of stay in Australia.

\begin{tabular}{|c|c|c|c|c|c|c|}
\hline Migration region & Total & Physical & Emotional & Social & School & Psychosocial \\
\hline \multicolumn{7}{|l|}{ Parents/a } \\
\hline Middle East & $81.15^{* *}$ & $92.19^{* *}$ & $85^{* *}$ & 90 & $75^{*}$ & 80 \\
\hline Former Yugoslavia & $86.96^{* *}$ & $93.75^{* *}$ & $85^{* *}$ & 97.5 & $85.42^{*}$ & 89.17 \\
\hline Africa & $91.30^{* *}$ & $100^{* *}$ & $100^{* *}$ & 90 & $87.5^{*}$ & 89.29 \\
\hline \multicolumn{7}{|l|}{ Adolescents } \\
\hline Middle East & 86.96 & $93.75^{* *}$ & 85 & 95 & 80 & 85 \\
\hline Former Yugoslavia & 90.22 & $96.875^{* *}$ & 90 & 100 & 85 & 87.5 \\
\hline Africa & 92.39 & $100^{* *}$ & 95 & 95 & 85 & 90 \\
\hline \multicolumn{7}{|l|}{ Parents/c } \\
\hline Middle East & $84.78^{* *}$ & $87.5^{* *}$ & $90^{* *}$ & 90 & $80^{*}$ & $85^{*}$ \\
\hline Former Yugoslavia & $89.13^{* *}$ & $93.75^{* *}$ & $85^{* *}$ & 95 & $86.25^{*}$ & $88.33^{*}$ \\
\hline Africa & $90.22^{* *}$ & $96.88^{* *}$ & $100^{* *}$ & 90 & $88.75^{*}$ & $90^{*}$ \\
\hline \multicolumn{7}{|l|}{ Pre-migration trauma } \\
\hline \multicolumn{7}{|l|}{ Parents/a } \\
\hline Yes & $78.26^{* *}$ & $89.06^{*}$ & $80^{* *}$ & $85^{*}$ & 75 & $76.67^{* *}$ \\
\hline No & $90.76^{* *}$ & $96.88^{*}$ & $100^{* *}$ & $100^{*}$ & 87.5 & $90.83^{* *}$ \\
\hline Declined & $87.47^{* *}$ & $96.88^{*}$ & $94.38^{* *}$ & $82.5^{*}$ & 75 & $82.60^{* *}$ \\
\hline \multicolumn{7}{|l|}{ Adolescents } \\
\hline Yes & 84.78 & 95.31 & 80 & $90^{*}$ & 80 & $78.33^{*}$ \\
\hline No & 93.48 & 96.88 & 90 & $100^{*}$ & 90 & $91.67^{*}$ \\
\hline Declined & 82.95 & 96.88 & 87.5 & $82.5^{*}$ & 80 & $77.50^{*}$ \\
\hline \multicolumn{7}{|l|}{ Parents/c } \\
\hline Yes & $85.23^{*}$ & 90.63 & $90^{*}$ & $85^{* *}$ & $75^{* *}$ & $81.67^{* *}$ \\
\hline No & $90.22^{*}$ & 93.75 & $95^{*}$ & $100^{* *}$ & $90.83^{* *}$ & $91.03^{* *}$ \\
\hline Declined & $85.87^{*}$ & 96.88 & $90^{*}$ & $80^{* * *}$ & $80^{* *}$ & $80^{* *}$ \\
\hline \multicolumn{7}{|c|}{ Length of stay in Australia (as reported by parents) } \\
\hline \multicolumn{7}{|c|}{ Parents/a $\mathrm{a}^{\mathrm{a}}$} \\
\hline More than 5 years & 82.61 & 93.75 & $80^{*}$ & 95 & 80.21 & 83.33 \\
\hline $2-5$ years & 89.13 & 96.88 & $95^{*}$ & 90 & 79.17 & 86.67 \\
\hline Less than 2 years & 89.13 & 100 & $85^{*}$ & 80 & 79.17 & 83.33 \\
\hline \multicolumn{7}{|l|}{ Adolescents $^{\mathrm{b}}$} \\
\hline More than 5 years & 89.13 & 93.75 & 90 & 100 & 85 & 88.33 \\
\hline 2 - 5 years & 90.22 & 100 & 90 & 95 & 80 & 87.92 \\
\hline Less than 2 years & 89.13 & 100 & 85 & 85 & 90 & 83.33 \\
\hline \multicolumn{7}{|l|}{ Parents/cc } \\
\hline More than 5 years & 85.87 & 90.63 & $90^{*}$ & 90 & 85 & 86.67 \\
\hline 2 - 5 years & 87.5 & 93.75 & $90^{*}$ & 90 & 83.33 & 86.67 \\
\hline Less than 2 years & 92.39 & 96.65 & $95^{*}$ & 100 & 90 & 94.17 \\
\hline
\end{tabular}

Note: As total and factor scores were significantly skewed, nonparametric tests, Spearman’s rho and the Kruskal-Wallis Rank Test were used. ${ }^{\mathrm{a} P a r}$ ents/a = parent-reports of adolescents; ${ }^{b}$ Adolescents = Adolescent self-reports; ${ }^{c}$ Parent $/ \mathrm{c}=$ parent-reports of children. ${ }^{* * *} p<0.01 ;{ }^{*} p<0.05$.

functioning (adolescents, $\chi^{2}=10.08, p=0.007$; children, $\chi^{2}=19.89, p=0.0001$ ); emotional functioning (adolescents, $\chi^{2}=10.08, p=0.007$; children, $\chi^{2}=16.01, p=0.0003$ ); school functioning (adolescent, $\chi^{2}=8.80, p=$ 
0.012; children, $\chi^{2}=9.07, p=0.011$ ); and psychosocial summary score for children, $\left(\chi^{2}=9.21, p=0.01\right)$. Regional/ethnic differences relating to the psychosocial summary score for adolescents approached statistical significance $\left.\chi^{2}=5.89, p=0.053\right)$. When a significant difference was found in PedsQL sub- or summary scale scores, African youth consistently indicated higher scores than their counterparts from the former Yugoslavia and the Middle East. Adolescent self-reports indicated a significant difference across regions in only the physical sub/summary score $\left(\chi^{2}=13.14, p=0.001\right)$.

Table 3 also depicts the relationship between PedsQL scores and pre-migration trauma. A significant association was observed in total scores for both adolescents $\left(\chi^{2}=10.14, p=0.006\right)$ and for children $\left(\chi^{2}=8.01, p=\right.$ $0.018)$ according to parent-reports whereas adolescents' self-reported total scores approached significance $\left(\chi^{2}=\right.$ $5.75, p=0.057)$. Significant relationships were also noted between experiencing trauma and subscale/summary scales of: physical functioning (adolescents: parent-reports, $\chi^{2}=6.66, p=0.036$ ); emotional functioning (adolescents: parent-reports, $\chi^{2}=18.69, p=0.0001$; child: parent-reports, $\chi^{2}=6.10 p=0.047$ ); social functioning (adolescents: parent-reports, $\chi^{2}=7.55, p=0.023$; self-reports, $\chi^{2}=14.30, p=0.001$; child: parent-reports, $\chi^{2}=$ 24.05, $p=0.0001$ ); school functioning (child: parent-reports, $\chi^{2}=18.08, p=0.0001$ ) and psychosocial functioning (adolescents: parent-reports, $\chi^{2}=11.44, p=0.003$; self-reports, $\chi^{2}=8.66, p=0.013$; child: parent-reports, $\chi^{2}=$ $16.84, p=0.0002)$. Generally, participants who reported experiencing trauma indicated lower HRQOL compared to those not reporting trauma.

Number of traumatic events experienced was significantly negatively correlated with adolescent self-reported social functioning $\left(r_{s}=-0.37, p=0.004\right)$ and to some degree with parent-reported adolescent social functioning $\left(r_{s}=-0.22, p=0.07\right)$. There were no other significant relationships observed between number of traumatic events and child/adolescent PedsQL scores. However, significant associations were detected between migration region and participants who reported being exposed to trauma (adolescents: parent-reports, $\chi^{2}=19.88, p=0.001$; self-reports, $\chi^{2}=29.68, p=0.000$; child: parent-reports, $\left.\chi^{2}=30.89, p=0.000\right)$. Accordingly, significantly more African parents/adolescents reported experiencing pre-migration trauma compared to people from former Yugoslavia and the Middle East.

The study also investigated the association between the length of stay in Australia (reported by parents) and participants' PedsQL scores (Table 3). Significant associations were found between parent-reported emotional functioning and years in Australia (less than 2 years, 2 - 5 years, more than 5 years) for adolescents $\left(\chi^{2}=8.06, p=\right.$ $0.018)$ and children $\left(\chi^{2}=6.10, p=0.047\right)$. Adolescents living in Australia for $2-5$ years appeared to have the highest emotional functioning (median $=95$ ), followed by those with less than 2 years (median $=85$ ) and those with more than 5 years (median $=80$ ) respectively. For children, greater emotional functioning was reported for those with less than 2 years (median =95), compared to a median of 90 for those with $2-5$ and more than 5 years. Other associations between length of stay and PedsQL total, summary or subscale scores were not significant at $p=0.05$. When considering years lived in Australia as continuous a significant relationship was seen for physical functioning (adolescent parent-report, $r_{s}=-0.17, p=0.03$; child parent-report, $r_{s}=-0.14, p=0.04$ ); for emotional functioning (child parent-report, $r_{s}=-0.23, p=0.0007$ ); and for social functioning (adolescent self-report $r_{s}=0.15, p=0.052$ ).

There were no significant associations between PedsQL total, summary or subscale scores and gender; as well as other sociodemographic variables such as religion, household income, family composition, and employment status.

Table 4 shows the median PedsQL scores according to reported health service utilisation by participants. Significant associations were observed in total scores for adolescents on parent-reports $\left(\chi^{2}=7.47, p=0.024\right)$ and self-report $\left(\chi^{2}=8.48, p=0.004\right.$ ); as well as the sub/summary scales of physical functioning (self-report, $\chi^{2}=$ 8.13, $p=0.004$ ); social (parent-report: $\chi^{2}=7.46, p=0.024$; self-report: $\chi^{2}=5.31, p=0.021$ ); emotional (self-report: $\chi^{2}=8.72, p=0.003$ ); school functioning (parent-report: $\chi^{2}=7.07, p=0.03$; self-report: $\chi^{2}=3.86, p=$ 0.05 ); and psychosocial functioning (parent-report: $\chi^{2}=7.97, p=0.02$; self-report: $\chi^{2}=6.56, p=0.01$ ). Adolescents accessing available health services had lower PedsQL total scores (parent, median $=72.83$; self-report, median $=76.09$ ) compared to those who did not access services (parent, median $=88.88$; self, median $=91.30$ ) . A similar trend was indicated for all subscale/summary scores (Table 4). There were no significant associations between service utilisation and PedsQL for children.

\section{Discussion}

A comparison of the results of the present study to those in Varni et al. [7] indicate that the HRQOL of refugee 
Table 4. Median paediatric quality of life (PedsQL) scores for adolescents and children according to reported service utilisation.

\begin{tabular}{|c|c|c|c|c|c|c|}
\hline Service utilisation & Total & Physical & Emotional & Social & School & Psychosocial \\
\hline \multicolumn{7}{|l|}{ Parents/a } \\
\hline Yes & $72.83^{*}$ & 84.38 & 77.5 & $75^{*}$ & $58.33^{*}$ & $70^{*}$ \\
\hline No & $88.88^{*}$ & 96.87 & 90 & $95^{*}$ & $83.33^{*}$ & $85.83^{*}$ \\
\hline Don’t know & $71.20^{*}$ & 79.69 & 72.5 & $70^{*}$ & $70.83^{*}$ & $71.67^{*}$ \\
\hline \multicolumn{7}{|l|}{ Adolescents } \\
\hline Yes & $76.09^{* *}$ & $84.38^{* *}$ & $65^{* *}$ & $90^{*}$ & $70^{*}$ & $75^{* *}$ \\
\hline No & $91.30^{* *}$ & $96.88^{* *}$ & $90^{* *}$ & $100^{*}$ & $85^{*}$ & $88.33^{* *}$ \\
\hline Missing & $90.22^{* *}$ & $100^{* *}$ & $85^{* *}$ & $92.5^{*}$ & $90^{*}$ & $83.33^{* *}$ \\
\hline \multicolumn{7}{|l|}{ Parents/c } \\
\hline Yes & 93.48 & 100 & 95 & 100 & 75 & 90 \\
\hline No & 86.36 & 90.63 & 90 & 90 & 83.33 & 86.67 \\
\hline Don’t know & 86.96 & 87.5 & 100 & 90 & 83.33 & 81.67 \\
\hline
\end{tabular}

Note: As total and factor scores were significantly skewed, Spearman's rho and the Kruskal-Wallis Rank Test were used to test relationships; Service utilisation assessed the use of mental health services during the previous six months with the aid of questions from the Child and Adolescent Component of the Australian National Survey of Mental Health and Wellbeing by M. G. Sawyer, B. Raphael, J. M. Rey, L. C. Whaites, S. R. Zubrick, F. Arney, ... M. R. Prior, 2001, The Australian and New Zealand Journal of Psychiatry, 35(6), 806 - 806. ${ }^{\mathrm{a} P a r e n t s / a}=$ parent-reports of adolescents; ${ }^{\mathrm{b}}$ Adolescents $=$ Adolescent self-reports; ${ }^{\mathrm{C}}$ Parent/c $=$ parent-reports of children. ${ }^{* *} p<0.01 ;{ }^{*} p<0.05$.

children and adolescents including their physical, emotional, social, and school functioning appear to be comparable to that of the general paediatric population. Approximately $15.5 \%$ of adolescents (self-report $=11.6 \%$ ) and $13 \%$ of children were below the cut-off point distinguishing healthy and at-risk populations. Although this percentage was lower than found by Varni et al. [7] (e.g. self-report: 17\%; parent-report: 18\%), a sizeable proportion of refugee children and adolescents appear to be suffering from or at risk for chronic health problems.

Studies with a similar regional/ethnic composition of refugee adolescents/children also reported lower rates of depressive symptomatology (7.2\%) as well as emotional and behavioural problems (psychiatric disorder possible, 6.7\%) compared with other refugee youth and the general population respectively [10] [12]. Although these findings may explain the enhanced HRQOL in the present population, they have to be interpreted cautiously. Despite several non-English versions of the PedsQL instrument being validated and/or previously used, reliability and validity data for the translated versions in the present study are unavailable. Cultural differences in the conceptualisation of illness and health [17], as well as over-reporting HRQOL_by both parents and adolescents - to appear more socially desirable or to avoid the stigma of mental illness, may reduce the significance of our findings. Alternatively, our results may reflect the resilience and high levels of functioning found in refugee children despite the considerable challenges they face [18] notwithstanding that other studies have found increased levels of psychological problems among refugee children compared with non-refugee children from ethnic minorities and mainstream white children [19].

There is a dearth of research exploring the cultural differences among refugee people. However, several reasons can be hypothesised for the robust relationship found between migration region/ethnicity and HRQOL including physical, emotional, school (adolescents and children), and psychosocial functioning (children only); as well as for the finding that African youth consistently appeared to outperform their peers from the former Yugoslavia and the Middle East; Middle Eastern youth indicated the poorest HRQOL. Previous research had already shown that Adolescents/children from the Middle East had more depressive symptoms than their colleagues from Africa and Europe [11].

Studies investigating refugee coping strategies have found that African adults and children make a conscious effort to avoid or forget past negative experiences through distraction (e.g. excelling in work and study), focusing on their present life's purpose (e.g. successful resettlement, building communities, reunifying families) and maintaining hope for the future [20] [21]. Their forward-looking mindset may enable African migrants to envision a future beyond past and present difficulties, facilitating their integration into mainstream society. This in- 
terpretation may be supported by the additional finding that African participants indicated greater quality of life despite reporting more trauma experiences than their counterparts from Europe and the Middle East. Conversely there is some evidence that refugees from former Yugoslavia may be preoccupied with pre-migration memories as a source of comfort and coping [22]. Maintaining religious beliefs for a sense of continuity in a volatile world is an important coping device among refugee youth [20] [23]. Therefore, negative perceptions in resettlement societies including Australia towards the Muslim community and reported in the media [24] [25] may impede the integration and sense of belongingness felt by Middle Eastern youth (the majority whom are Muslims), reducing their HRQOL. Nonetheless future research is needed to explore potential differences in coping styles in refugee communities as well as stigmatisation of health/mental health concerns, and barriers to accessing services. It is also important for practitioners to increase their awareness of the plethora of acculturation stressors, including identity confusion, encountered by different groups of young refugees in host countries, as well their resilience and unique coping resources and strategies that contribute to better HRQOL and can be incorporated into therapeutic work (e.g. [26]).

The finding that 4 - 17 years old with pre-migration trauma showed significantly lower HRQOL compared to those who did not report traumatic experiences indicates that trauma is associated with a greater health risk; and by extension may lend support to the dose-effect relationship between greater trauma exposure and higher rates of psychiatric illness [27]. This result was robust across total, factor and summary scores for both children and adolescents except physical (adolescents) and school (children) functioning, indicating that traumatic experience can substantially enhance the risk of mental illness (e.g. [6]). However these outcomes are somewhat confounded by African participants reporting both higher HRQOL and more pre-migratory traumatic experiences. Hence, it is important that future research verify these unprecedented preliminary findings, using more vigorous measures to assess trauma exposure; and also explore possible explanations for African children's enhanced resilience, with the aid of appropriate qualitative methodologies.

The number of traumatic events did not appear to predict HRQOL except for adolescents' social functioning (self-report); may be because adolescents' were in addition negatively impacted by their parents' traumatisation and/or social, financial and other settlement struggles more than children; but their social difficulties remained unknown to their parents. This result however, could be influenced by the relatively low number of traumatic events reported — either because of the reluctance to afford details, memory lapses, or because refugee status is granted to people with less traumatic exposure (e.g. [28]).

Length of stay in Australia predicted emotional functioning with adolescents 2 - 5 years in Australia and children with less than 2 years, indicating the highest HRQOL. Increasing length of stay also appeared to negatively impact on children's emotional functioning. Regarding adolescents, a plausible reason is that although they struggle during the initial years to learn English and make new friends, thereafter a sense of agency and mastery at their newly acquired skills contribute to positive emotions. With time, advancing age and corresponding cognitive complexity they may begin to perceive added stressors such as discrimination, and intergenerational and cultural conflicts with parents, negatively impacting their emotional functioning [29] [30]. Conversely, lesser cognitive capacity to fully comprehend the implication of acculturation stressors might explain why children with less than 2 years in Australia had better emotional functioning than their peers with longer residence, but why this tended to deteriorate with time. Practitioners and policy makers need to take these complexities into consideration when designing and implementing services and interventions for refugee paediatric populations.

Only a small percentage of participants reported accessing mental health care services and supports- $3.2 \%$ of children and $6.3 \%$ of adolescents (self-report, 9.6\%)—with a strong association between service utilisation and adolescents' overall HRQOL, psychosocial, social and school functioning (parent- and self-report), as well as physical and emotional functioning (self-report alone). Additionally, the HRQOL of adolescents not accessing mental health services was higher than those who did possibly because people who access services have mental/physical problems that reduce their quality of life. This may however also indicate dissatisfaction and/or negative perception of services utilised. No significant association was found between service utilisation and children's HRQOL indicating that adolescents may be especially at risk for mental illness (e.g. [31]). The low rate of reported service utilisation could however, have compromised the findings.

Hence, policy makers and practitioners need to consistently assess the cultural relevancy and utility value of formal services offered to refugee youth and others from culturally and linguistically diverse (CaLD) backgrounds. It may be useful for clinicians and other mental health practitioners to give particular consideration to culturally-oriented conceptual differences in mental health and the perceived stigmatisation associated with 
mental illness when working with refugee adolescents and children. Future efforts are also required to validate existing instruments or develop more culturally congruent methods to assess CaLD paediatric populations. The HRQOL measure with its holistic approach to wellbeing appears especially useful in this regard. There is also a need to move beyond traumatisation and focus on improving their physical, emotional and social wellbeing as envisaged by the World Health Organisation [32] and measured by HRQOL.

There were several limitations to the study. The validity and reliability of the PedsQL has not been tested with refugee children and adolescents from the cultural backgrounds in this study, although other language versions have been validated [15] [16]. Using convenience and snowball sampling was less desirable but inevitable due to the non-availability of a complete sampling frame. This makes generalization from study findings difficult. Additionally, data analyses were complicated by missing data and the skewness of the score distributions limited analyses to non-parametric methods. Missing and/or incomplete data also necessitated the exclusion of 46 participants (approximately $0.064 \%$ of the total). Finally, the non-inclusion of a control group did not allow for comparisons with non-refugee migrants and mainstream paediatric populations.

\section{Conclusion}

The present study explored the sociodemographic predictors of HRQOL and the relationship between mental health care service utilisation and HRQOL. The findings revealed that participants' region/ethnicity, pre-migration trauma exposure, and a lesser degree length of Australian residency were significantly associated with HRQOL and/or its composite functional dimensions. Africans of 4 - 17 years old appear to have the highest HRQOL compared to those from former Yugoslavia and the Middle East. A negative association was established between service utilisation and PedsQL with those who accessed services demonstrating lower HRQOL. There was also some indication that refugee children and adolescents were no more at risk for chronic health problems than the general population. Mental health practitioners, policy makers and researchers will nonetheless benefit from enhanced awareness of the cultural differences across refugee communities regarding the unique challenges faced and coping strategies utilised. Designing and evaluating interventions and service provision modalities that incorporate culturally accepted practices will undoubtedly benefit service utilisers from refugee and other CaLD backgrounds.

\section{Acknowledgements}

This study was supported by a grant from the Australian Research Council and the Migrant Resource Centre of South Australia (MRCSA), the Industry Partner. We wish to thank parents, adolescents and MRCSA and their staff. Our research assistants included: Ms Bev Rundle and Ms Lynda Caudle.

\section{References}

[1] United Nations High Commission for Refugees (UNHCR) (2015) Global Trends Report 2014. http://www.unhcr.org/54aa91d89.html

[2] Department of Immigration and Citizenship (DIAC) (2013) Australia’s Offshore Humanitarian Program: 2012-13. http://www.immi.gov.au/media/publications/statistics/immigration-update/australia_offshore_humanitarian_prog_2012 -13.pdf

[3] Fazel, M., Wheeler, J. and Danesh, J. (2005) Prevalence of Serious Mental Disorder in 7000 Refugees Resettled in Western Countries: A Systematic Review. Lancet, 365, 1309. http://dx.doi.org/10.1016/S0140-6736(05)61027-6

[4] Porter, M. and Haslam, N. (2005) Predisplacement and Postdisplacement Factors Associated with Mental Health of Refugees and Internally Displaced Persons: A Meta-Analysis. Journal of the American Medical Association, 294, 602612. http://dx.doi.org/10.1001/jama.294.5.602

[5] Summerfield, D. (2000). Childhood, War, Refugeedom and 'Trauma': Three Core Questions for Mental Health Professionals. Transcultural Psychiatry, 37, 417-433. http://dx.doi.org/10.1177/136346150003700308

[6] Almqvist, K. and Brandell-Forsberg, M. (1997) Refugee Children in Sweden: Post-Traumatic Stress Disorder in Iranian Preschool Children Exposed to Organized Violence. Child Abuse \& Neglect, 21, 351-366. http://dx.doi.org/10.1016/S0145-2134(96)00176-7

[7] Varni, J.W., Burwinkle, T.M., Seid, M. and Skarr, D. (2003) The PedsQL ${ }^{\text {TM* }} 4.0$ as a Pediatric Population Health Measure: Feasibility, Reliability, and Validity. Ambulatory Pediatrics, 3, 329-341. http://dx.doi.org/10.1367/1539-4409(2003)003<0329:TPAAPP>2.0.CO;2 
[8] Fazel, M., Reed, R.V., Panter-Brick, C. and Stein, A. (2012) Mental Health of Displaced and Refugee Children Resettled in High-Income Countries: Risk and Protective Factors. The Lancet, 379, 266-282. http://dx.doi.org/10.1016/S0140-6736(11)60051-2

[9] De Anstiss, H., Ziaian, T., Procter, N., Warland, J. and Baghurst, P. (2009) Help-Seeking for Mental Health Problems in Young Refugees: A Review of the Literature with Implications for Policy, Practice, and Research. Transcultural Psychiatry, 46, 584-607. http://dx.doi.org/10.1177/1363461509351363

[10] Ziaian, T., de Anstiss, H., Antoniou, G., Baghurst, P. and Sawyer, M. (2011) Emotional and Behavioural Problems among Refugee Children and Adolescents Living in South Australia. Australian Psychologist, 48, 139-148.

[11] Ziaian, T., de Anstiss, H., Antoniou, G., Sawyer, M.G. and Baghurst, P. (2012) Depressive Symptomatology and Service Utilisation among Refugee Children and Adolescents Living in South Australia. Child and Adolescent Mental Health, 17, 146-152. http://dx.doi.org/10.1111/j.1475-3588.2011.00620.x

[12] Sawyer, M.G., Arney, F., Baghurst, P., Clark, J., Graetz, B., Kosky, R., et al. (2001) The Mental Health of Young People in Australia: Key Findings from the Child and Adolescent Component of the National Survey of Mental Health and Well-Being. Australian and New Zealand Journal of Psychiatry, 35, 806-814. http://dx.doi.org/10.1046/j.1440-1614.2001.00964.x

[13] Varni, J.W., Limbers, C.A. and Burwinkle, T.M. (2007) Parent Proxy-Report of Their Children's Health-Related Quality of Life: An Analysis of 13,878 Parents' Reliability and Validity across Age Subgroups Using the PedsQL 4.0 Generic Core Scales. Health and Quality of Life Outcomes, 5, 2. http://dx.doi.org/10.1186/1477-7525-5-2

[14] Varni, J.W., Seid, M. and Kurtin, P.S. (2001) PedsQL тм 4.0: Reliability and Validity of the Pediatric Quality of Life Inventory (TM) Version 4.0 Generic Core Scales in Healthy and Patient Populations. Medical Care, 39, 800-812. http://dx.doi.org/10.1097/00005650-200108000-00006

[15] Gkoltsiou, K., Dimitrakaki, C., Tzavara, C., Papaevangelou, V., Varni, J.W. and Tountas, Y. (2008) Measuring HealthRelated Quality of Life in Greek Children: Psychometric Properties of the Greek Version of the Pediatric Quality of Life Inventory TM 4.0 Generic Core Scales. Quality of Life Research, 17, 299-305. http://dx.doi.org/10.1007/s11136-007-9294-1

[16] Roizen, M., Rodríguez, S., Bauer, G., Medin, G., Bevilacqua, S., Varni, J.W. and Dussel, V. (2008) Initial Validation of the Argentinean Spanish Version of the PedsQL ${ }^{\text {TM }}$ 4.0 Generic Core Scales in Children and Adolescents with Chronic Diseases: Acceptability and Comprehensibility in Low-Income Settings. Health and Quality of Life Outcomes, 6, 59. http://dx.doi.org/10.1186/1477-7525-6-59

[17] Kleinman, A. (1987) Anthropology and Psychiatry. The Role of Culture in Cross-Cultural Research on Illness. The British Journal of Psychiatry, 151, 447-454. http://dx.doi.org/10.1192/bjp.151.4.447

[18] Ziaian, T., de Anstiss, H., Antoniou, G., Baghurst, P. and Sawyer, M.G. (2012) Resilience and Its Association with Depression, Emotional and Behavioural Problems, and Mental Health Service Utilisation among Refugee Adolescents Living in South Australia. International Journal of Population Research, 2012, 1-9. http://dx.doi.org/10.1155/2012/485956

[19] Fazel, M. and Stein, A. (2003) Mental Health of Refugee Children: Comparative Study. British Medical Journal, 327, 134-134. http://dx.doi.org/10.1136/bmj.327.7407.134

[20] Goodman, J.H. (2004) Coping with Trauma and Hardship among Unaccompanied Refugee Youths from Sudan. Qualitative Health Research, 14, 1177-1196. http://dx.doi.org/10.1177/1049732304265923

[21] Luster, T., Qin, D.B., Bates, L., Johnson, D.J. and Rana, M. (2008) The Lost Boys of Sudan: Ambiguous Loss, Search for Family, and Reestablishing Relationships with Family Members. Family Relations, 57, 444-456. http://dx.doi.org/10.1111/j.1741-3729.2008.00513.x

[22] Miller, K.E., Worthington, G.J., Muzurovic, J., et al. (2002) Bosnian Refugees and the Stressors of Exile: A Narrative Study. American Journal of Orthopsychiatry, 72, 341-354. http://dx.doi.org/10.1037/0002-9432.72.3.341

[23] Raghallaigh, M.N. (2011) Religion in the Lives of Unaccompanied Minors: An Available and Compelling Coping Resource. British Journal of Social Work, 41, 539-556. http://dx.doi.org/10.1093/bjsw/bcq136

[24] Kabir, N. (2006) Representation of Islam and Muslims in the Australian Media, 2001-2005 1. Journal of Muslim Minority Affairs, 26, 313-328. http://dx.doi.org/10.1080/13602000601141281

[25] Wike, R. and Grim, B.J. (2010) Western Views toward Muslims: Evidence from a 2006 Cross-National Survey. International Journal of Public Opinion Research, 22, 4-25. http://dx.doi.org/10.1093/ijpor/edq002

[26] Rousseau, C., Key, F. and Measham, T. (2005) The Work of Culture in the Treatment of Psychosis in Migrant Adolescents. Clinical Child Psychology and Psychiatry, 10, 305-317. http://dx.doi.org/10.1177/1359104505053751

[27] Mollica, R.F., McInnes, K., Pham, T., Fawzi, M., Murphy, E. and Lin, L. (1998) The Dose-Effect Relationships between Torture and Psychiatric Symptoms in Vietnamese Ex-Political Detainees and a Comparison Group. The Journal of Nervous and Mental Disease, 186, 543-553. http://dx.doi.org/10.1097/00005053-199809000-00005 
[28] Silove, D., Steel, Z., Susljik, I., Frommer, N., Loneragan, C., Brooks, R., et al. (2006) Torture, Mental Health Status and the Outcomes of Refugee Applications among Recently Arrived Asylum Seekers in Australia. International Journal of Migration, Health and Social Care, 2, 4-14. http://dx.doi.org/10.1108/17479894200600002

[29] Renzaho, A., Green, J., Mellor, D. and Swinburn, B. (2011) Parenting, Family Functioning and Lifestyle in a New Culture: The Case of African Migrants in Melbourne, Victoria, Australia. Child \& Family Social Work, 16, 228-240. http://dx.doi.org/10.1111/j.1365-2206.2010.00736.x

[30] Renzaho, A., McCabe, M. and Sainsbury, W.J. (2011) Parenting, Role Reversals and the Preservation of Cultural Values among Arabic Speaking Migrant Families in Melbourne, Australia. International Journal of Intercultural Relations, 35, 416-424. http://dx.doi.org/10.1016/j.ijintrel.2010.09.001

[31] McNamara, P.M. (2012) Adolescent Suicide in Australia: Rates, Risk and Resilience. Clinical Child Psychology and Psychiatry, 18, 351-369.

[32] WHOQOL Group (1997) Measuring Quality of Life. The World Health Organization Quality of Life Instruments (The WHOQOL-100 and the WHOQOL-Bref), WHO, Geneva. 